\title{
Retrospective Study on the Occurrence of Reportable Priority Cattle Diseases in Southern Nations, Nationalities and Peoples' Regional State, Southern Ethiopia
}

\author{
Semayat Oyda ${ }^{1}$, Rahmeto Abebe $^{2} \&$ Bekele Megersa $^{2}$ \\ ${ }^{1}$ Wolaita Sodo University Dawuro - Tarcha Campus, department of Animal and Range Science, P. O. Box 01, \\ Tarcha, Ethiopia \\ ${ }^{2}$ Hawassa University School of Veterinary Medicine, P.O. Box 05, Hawassa, Ethiopia \\ Correspondence: Semayat Oyda, School of Veterinary Medicine, Wolaita Sodo University, Dawuro, Tarcha \\ campus, Ethiopia. E-mail: drsemayat@gmail.com, semayatoy79@gmail.com. Tel: 251-910-049-011/251-926- \\ 089-330
}

Received: December 1, 2019 Accepted: December 25, 2019 Online Published: January 4, 2020

\begin{abstract}
A retrospective study was conducted between October 2016 and March 2017 in Southern Nations, Nationalities and Peoples Regional State (SNNPRS) to identify major reportable cattle disease outbreaks. The retrospective study was based on a nine years (2007-2015) cattle disease outbreak report data retrieved from the Ministry of Livestock and Fisheries (MoLF) data bases. The retrospective study revealed that of the 15,840 disease outbreak reports expected from SNNPRS, only 1,578 (11\%) reports were submitted to MoLF during the nine years' time. According to the data retrieved from MoLF, a total of 1,496 cattle disease outbreaks with 44,646 morbidity cases and 4,709 mortalities were recorded in SNNPRS over the nine years period. The outbreaks were caused by blackleg (40.6\%), hemorrhagic septicemia (HS) (26.3\%), lumpy skin disease (LSD) (16\%), anthrax (11.4\%), foot and mouth disease (FMD) (4.7\%), contagious bovine pleuropneumonia (CBPP) $(0.8 \%)$ and rabies $(0.3 \%)$ in decreasing order of their proportion. LSD was responsible for the highest proportion of morbidity cases $(35.9 \%)$ followed by FMD (26.2\%) while blackleg and LSD were the leading causes of cattle mortalities, which accounted for $31 \%$ and $30.2 \%$ of the deaths recorded, respectively. In contrast, the lowest number of outbreaks, morbidity and mortality of cattle was caused by rabies. Disease outbreaks were occurred in all the seasons of the year; however, relatively higher number of outbreaks (30.7\%) was recorded in early dry season (September to November).

In conclusion, the retrospective study has shown a very low level of disease outbreak reporting rate in SNNPRS, which may be due to misreporting or no outbreak of diseases.
\end{abstract}

Keywords: constraints, Epidemic disease, outbreak, seasons, retrospective

\section{Introduction}

According to recent estimates, Ethiopia has 56.71 million cattle, 29.33 million sheep, 29.11 million goats, 1.16 million camels and 56.87 million poultry (CSA, 2015). The predominant livestock production system in Ethiopia is extensive, where indigenous breeds are kept under low-input/low-output husbandry practices. Despite the huge resource, Ethiopia's livestock productivity is lower than the Africa's average. The major biological constraints contributing to low productivity include low genetic potential of the animals, poor nutrition and the prevailing animal diseases (CSA, 2011). The main effect of the diseases include mortality, low production, reduced quality of animal products such as milk and meat, decreased drought power and risk of zoonotic diseases to man (Sindato et al., 2011). Ethiopia ranks highest in Africa in the health burden of zoonotic diseases (Grace et al., 2012).

In Ethiopia, there are several endemic and epidemic animal diseases caused by bacteria, viruses, protozoa, and parasites that compromise the productivity of the livestock sector. Among, the most important diseases are: LSD, CBPP, FMD, Blackleg, Anthrax, Hemorrhagic septicemia and so on (LDMFSB, 2016). The spatial distribution of major priority diseases among African countries in 2010 mirrors that of the previous years with a significant number of countries affected by LSD (63.26\%), CBPP (48.97\%) and FMD (48.97\%) (PAAHYB, 2010). Risk factors for disease occurrences are host factors, environmental factors, pathogen factors and climate condition are the most important (Radostits et al., 2007; Bayissa et al., 2011). 
Most of diseases are transmitted and gain entrance to the body by ingestion, inhalation, or through the skin contact (Fasanella et al., 2011; Hugh-Jones \& Blackburn, 2009). The most serious priority diseases are caused by rapidly transmitting pathogens that produce acute and serious disease in large numbers of hosts (Grace et al., 2015). Their occurrence is maintained when an agent and susceptible hosts are present in adequate numbers, and the agent can be effectively conveyed from a source to the susceptible hosts (CDC, 2012).

The controlling and management measures involve treating the cases, preventing further spread of the disease, monitoring the effects of control measures (Bonita et al., 2006; Radostits et al., 2007; Tuppurainen, 2005) and ring vaccination is sometimes termed 'emergency vaccination' (all susceptible animals on farms within a certain radius of the farm (Ellis, 1994) and movement restriction (Holleman, 2002; Steffen et al., 1998). In Ethiopia, priority was given to decreasing the morbidity and the mortality of production related diseases (mainly external and internal parasites); to trade-limiting diseases (FMD, ovine/caprine pox, LSD, CBPP); and to the prevention of other economically important diseases (blackleg and anthrax) (ELMP, 2015).

Therefore, the objective of the study was to identify major priority reportable cattle disease outbreaks and seasonal occurrences in selected districts of Southern Nations, Nationalities and Peoples' Regional State.

\section{Materials and Methods}

\subsection{Study Area}

The study was conducted in Southern Nations, Nationalities and Peoples' Regional State (SNNPRS) in 2017 which has 14 zones (139 woredas) and 4 special districts. Geographically, the region is located between $4.43-8.58^{\circ}$ $\left(6.505^{\circ}\right)$ North latitude and $34.88-39.14^{\circ}\left(37.01^{\circ}\right)$ East longitude and agro-ecologically characterized as semidesert (6.2\%), Kolla (lowland) (49.8\%), woynadega (midland) (36.5\%) and dega (highland) (7.5\%) Total cattle population of the region is 11,215,636 (BoLFR, 2016).

\subsection{Study Design and Sample Size}

Retrospective study design was employed to conduct priority reportable cattle disease outbreaks of nine years' data (2007-2015) which was extracted from the Ministry of Livestock and Fishery (MoLF) disease outbreak record data bases as well as from Livestock and Fishery Bureau of SNNPRS. Disease outbreak reports collected from all zones and special districts in the region were searched thoroughly. The disease outbreaks reported in nine (9) were anthrax, blackleg, contagious bovine pleuropneumonia, foot-and-mouth disease, hemorrhagic septicemia and rabies. For retrospective study of cattle disease outbreaks, all zone and special districts found in SNNPRS were included in the study irrespective of the frequency and regularity of reporting to the MoLF or to SNNPRS Bureau of Livestock and Fishery. Among 14 zones and four special districts, most have reported outbreak cases less than $50 \%$.

\subsection{Data Collection}

A nine - years (2007-2015) data about priority reportable cattle disease occurred in all zones and special districts was collected from disease outbreak record databases in SNNPRS Bureau of Livestock and Fishery Resource and Ministry of Livestock and Fishery (MoLF) on specially designed format.

\subsection{Statistical Analysis}

Descriptive statistics was used to summarize the number of outbreaks, cases and deaths occurred during the nine year period (2007-2015) by administrative zone, type of disease and month and year of occurrence.

\section{Results}

Total number of disease outbreaks, morbidity cases and deaths in cattle reported from Southern Nations, Nationalities and Peoples' Regional State (SNNPRS) during the nine year period (2007-2015) has been summarized by zone and special districts in Table 1. Data were obtained for 14 administrative zones and four special districts. As a rule, each district must report to the Ministry of Livestock and Fisheries (MoLF) about livestock disease outbreaks (whether an outbreak occurs or not) once every month. Accordingly, the total number of reports expected from all zones/ districts in SNNPRS during the nine-year period was 15,840 but total reports submitted were only 1,578 (11\%). The highest reporting rate was made by Sidama Zone (40\%) followed by Halaba Special district (28.7\%) and the lowest was made by Gedeo Zone (0.5\%). The data retrieved revealed that a total of outbreak, morbidity and death were 1,496, 44,646 and 4,709 respectively from different causes over the nine year period. Among the administrative zones, the highest numbers of disease outbreaks were reported from Sidama zone $(51.6 \%)$ while cattle morbidity and death case reports were relatively higher in Kefa Zone. 
Table 1. Total number of cattle disease outbreaks, morbidity and deaths reported during the period 2007 to 2015 from SNNPRS

\begin{tabular}{llllll}
\hline Zone/Special District & No. of reports expected & No. of reports submitted & Total Outbreak & Total cases & Total deaths \\
\hline Alaba SD & 108 & $31(28.7)$ & $29(2)$ & $511(1.1)$ & $154(3.3)$ \\
Amaro SD & 108 & $1(0.9)$ & $1(0.07)$ & $8(0.02)$ & $5(0.11)$ \\
Basketo SD & 108 & $3(2.8)$ & $3(0.2)$ & $104(0.23)$ & $13(0.28)$ \\
Benchi Maji & 1080 & $20(1.9)$ & $20(1.3)$ & $2259(5.1)$ & $217(4.6)$ \\
Burji SD & 108 & $3(2.8)$ & $3(0.2)$ & $196(0.44)$ & $1(0.02)$ \\
Dawuro & 540 & $3(0.6)$ & $3(0.2)$ & $36(0.08)$ & $11(0.23)$ \\
Derashe SD & 108 & $3(2.8)$ & $3(0.2)$ & $66(0.15)$ & $13(0.27)$ \\
Gamo Gofa & 1620 & $42(2.6)$ & $41(2.7)$ & $1563(3.5)$ & $200(4.2)$ \\
Gedeo & 648 & $3(0.5)$ & $3(0.2)$ & $19(0.04)$ & $5(0.11)$ \\
Gurage & 1404 & $160(11.4)$ & $159(10.6)$ & $2905(6.5)$ & $404(8.6)$ \\
Hadiya & 1080 & $49(4.5)$ & $46(3.1)$ & $8887(19.9)$ & $165(3.5)$ \\
Kefa & 1080 & $182(16.9)$ & $164(11)$ & $11842(26.5)$ & $1471(31.2)$ \\
Kembata Tambaro & 756 & $28(3.7)$ & $27(1.8)$ & $303(0.67)$ & $70(1.5)$ \\
South Omo & 864 & $29(3.4)$ & $28(1.9)$ & $1514(3.39)$ & $159(3.4)$ \\
Sheka & 324 & $6(1.9)$ & $6(0.4)$ & $165(0.37)$ & $29(0.62)$ \\
Sidama & 2052 & $820(40)$ & $772(51.6)$ & $8090(18.1)$ & $1210(25.7)$ \\
Silti & 972 & $24(2.5)$ & $23(1.5)$ & $587(1.31)$ & $113(2.4)$ \\
Wolaita & 1296 & $171(13.2)$ & $165(11)$ & $5591(12.5)$ & $469(10)$ \\
\hline \hline Total & 14,256 & $1578(11)$ & 1,496 & 44,646 & 4.709 \\
\hline - Special Distris & & & & \\
\end{tabular}

$\mathrm{SD}=$ Special District

A value in the parenthesis indicates the respective proportion for each zone/special district from the total outbreaks, cases and deaths recorded during the nine year

Based on the report of symptomatic diagnosis the outbreaks were caused by seven diseases, namely Anthrax, Blackleg, Hemorrhagic Septicemia (HS), Foot-and-Mouth disease (FMD), Contagious Bovine Pleuro-pnuemonia (CBPP), Lumpy Skin Disease (LSD) and Rabies. The highest proportion of outbreaks were caused by blackleg (40.6\%) followed by HS (26.3\%), LSD (16\%), anthrax (11.4\%), FMD (4.7\%), CBPP $(0.8 \%)$ and rabies $(0.3 \%)$ in that order. LSD was responsible for the highest proportion of morbidity cases (35.9\%) followed by FMD (26.2\%). Blackleg and LSD were the leading causes of cattle mortalities, which accounted for $31 \%$ and $30.2 \%$ of the deaths recorded respectively. In contrast, the lowest number of outbreaks, morbidity and mortality of cattle was report to be rabies (Table 2).

Table 2. Number of outbreaks, morbidity and deaths reported during 2007-2015 in SNNPRS

\begin{tabular}{lllllll}
\hline Diseases & Outbreaks & \multicolumn{3}{l}{ Morbidity cases } & \multicolumn{2}{l}{ Mortality cases } \\
\cline { 2 - 7 } & $\begin{array}{l}\text { Total } \\
\text { number }\end{array}$ & Proportion (\%) & $\begin{array}{l}\text { Total } \\
\text { number }\end{array}$ & Proportion (\%) & $\begin{array}{l}\text { Total } \\
\text { number }\end{array}$ & Proportion (\%) \\
Anthrax & 170 & 11.4 & 1,604 & 3.6 & 715 & 15.2 \\
Blackleg & 607 & 40.6 & 9,092 & 20.4 & 1,461 & 31.0 \\
CBPP & 12 & 0.8 & 320 & 0.7 & 48 & 1 \\
FMD & 71 & 4.7 & 11,700 & 26.2 & 123 & 2.6 \\
HS & 393 & 26.3 & 5,844 & 13.1 & 905 & 19.2 \\
LSD & 239 & 16 & 16,043 & 35.9 & 1,420 & 30.2 \\
Rabies & 4 & 0.3 & 43 & 0.1 & 37 & 0.8 \\
\hline Total & $\mathbf{1 , 4 9 6}$ & $\mathbf{1 0 0}$ & $\mathbf{4 4 , 6 4 6}$ & $\mathbf{1 0 0}$ & $\mathbf{4 , 7 0 9}$ & $\mathbf{1 0 0}$ \\
\hline
\end{tabular}


When the temporal pattern of top five most frequently occurred disease outbreaks was evaluated over the nine years period, all diseases showed a tendency to decline with time. The highest number of outbreaks from all causes was recorded in 2008 while the lowest in 2015. FMD outbreaks were not recorded during the period 2007-2009. Since the total number of outbreaks caused by CBPP and rabies were so small that it was not possible to clearly show the temporal pattern of the diseases (Figure 1).

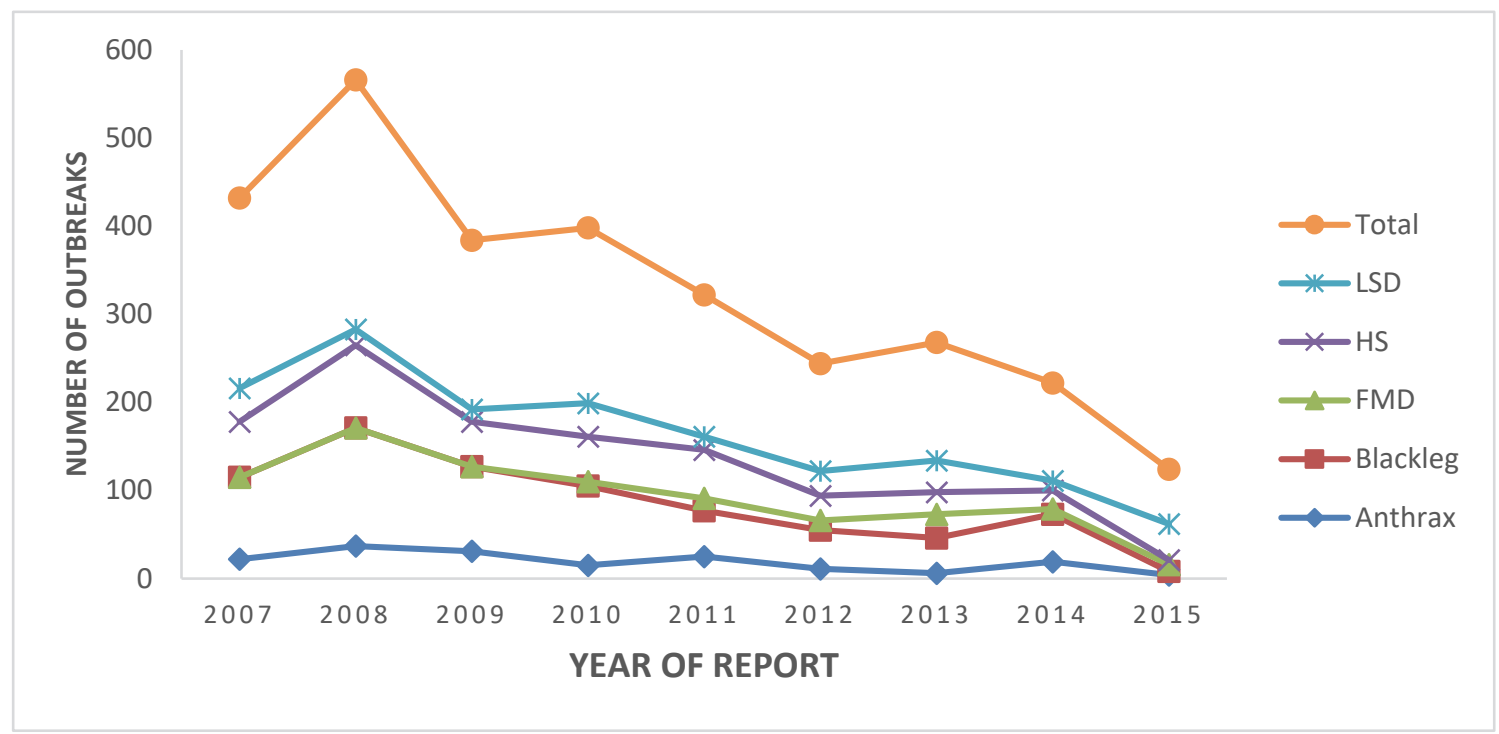

Figure 1. Temporal distribution of major cattle disease outbreaks in SNNPRS from 2007-2015

The spatial distribution of the seven diseases reported during the nine year period has been shown by zone and special district in Table 3. It was shown that more than 50\% of anthrax outbreaks were reported from two zones (Wolaita and Sidama) and about 56\% blackleg, 72\% HS and 34.7\% LSD reports were from Sidama zone. CBPP outbreaks were reported from Gamo-Gofa, South Omo and Guraghe zones and Basketo special district while rabies from Sidama, Sheka and South Omo zones only.

Table 3. Spatial distribution of disease outbreaks recorded by disease type

\begin{tabular}{lllllllll}
\hline Zone/special District & \multicolumn{9}{l}{ No. of outbreaks recorded by disease type } \\
\cline { 2 - 8 } & Anthrax & Blackleg & CBPP & FMD & HS & LSD & Rabies & Total \\
Alaba SD & 21 & 1 & 0 & 1 & 0 & 6 & 0 & 29 \\
Amaro SD & 0 & 0 & 0 & 0 & 1 & 0 & 0 & 1 \\
Basketo SD & 0 & 1 & 2 & 0 & 0 & 0 & 0 & 3 \\
Benchi Maji & 3 & 1 & 0 & 7 & 3 & 6 & 0 & 20 \\
Burji SD & 1 & 0 & 0 & 1 & 0 & 1 & 0 & 3 \\
Dawuro zone & 1 & 1 & 0 & 0 & 1 & 0 & 0 & 3 \\
Derashe SD & 0 & 3 & 0 & 0 & 0 & 0 & 0 & 3 \\
Gamo Gofa zone & 3 & 17 & 5 & 3 & 1 & 12 & 0 & 41 \\
Gedeo zone & 0 & 0 & 0 & 1 & 1 & 1 & 0 & 3 \\
Guraghe zone & 0 & 65 & 1 & 9 & 44 & 40 & 0 & 159 \\
Hadiya zone & 5 & 15 & 0 & 11 & 5 & 10 & 0 & 46 \\
Kefa zone & 10 & 66 & 0 & 16 & 36 & 36 & 0 & 164 \\
Kembata Ta. Zone & 13 & 10 & 0 & 1 & 1 & 2 & 0 & 27 \\
South Omo zone & 1 & 12 & 4 & 2 & 3 & 5 & 1 & 28 \\
Sheka zone & 0 & 1 & 0 & 1 & 0 & 3 & 1 & 6 \\
\hline
\end{tabular}




\begin{tabular}{lllllllll}
\hline Sidama zone & 50 & 340 & 0 & 14 & 283 & 83 & 2 & 772 \\
Silti zone & 8 & 5 & 0 & 2 & 1 & 7 & 0 & 23 \\
Wolaita zone & 54 & 69 & 0 & 2 & 13 & 27 & 0 & 165 \\
Total & 170 & 607 & 12 & 71 & 393 & 239 & 4 & 1496 \\
\hline
\end{tabular}

$\mathrm{SD}=$ Special district

The number of cattle vaccinated in nine years' period against the seven diseases reported is presented in Table 4 . It was noted that nearly 2 million cattle were vaccinated for all diseases during the period; however, the vaccination coverage varied from disease to disease. The highest proportion of vaccination was done for LSD (36.8\%) and the lowest for CBPP $(0.3 \%)$ while no vaccination was done for rabies.

Table 4. Vaccine coverage of outbreak by disease in nine years' (2007 - 2015 GC) in SNNPR

\begin{tabular}{lllllllll}
\hline Year & \multicolumn{7}{l}{ Number of cattle vaccinated by disease types } \\
\hline & Anthrax & Blackleg & CBPP & FMD & HS & LSD & Rabies & Total sum \\
$\mathbf{2 0 0 7}$ & 15239 & 73370 & 0 & 0 & 61156 & 43520 & 0 & 193,285 \\
$\mathbf{2 0 0 8}$ & 19620 & 82680 & 0 & 0 & 92201 & 21280 & 0 & 215,781 \\
$\mathbf{2 0 0 9}$ & 25516 & 67698 & 2194 & 0 & 60893 & 40560 & 0 & 196,861 \\
$\mathbf{2 0 1 0}$ & 21246 & 62835 & 0 & 824 & 31731 & 97257 & 0 & 213,893 \\
$\mathbf{2 0 1 1}$ & 57947 & 43503 & 0 & 86000 & 32561 & 50300 & 0 & 270,311 \\
$\mathbf{2 0 1 2}$ & 9790 & 56605 & 0 & 14783 & 72939 & 142373 & 0 & 296,490 \\
$\mathbf{2 0 1 3}$ & 14150 & 37304 & 0 & 35393 & 34653 & 175207 & 0 & 296,707 \\
$\mathbf{2 0 1 4}$ & 20222 & 53286 & 3500 & 750 & 29224 & 21390 & 0 & 128,372 \\
$\mathbf{2 0 1 5}$ & 7665 & 18019 & 0 & 500 & 864 & 133034 & 0 & 160,082 \\
Total & 191,395 & 495,300 & 5694 & 138,250 & 416,222 & 724,921 & 0 & $1,971,782$ \\
\hline
\end{tabular}

Seasonal distribution of outbreaks from each disease is presented in Table 5. It can be noted that disease outbreaks from all causes, except rabies, were reported in all seasons of the year. However, the highest frequency of occurrence especially due to blackleg, FMD, HS and LSD was recorded in the early dry season (Sep - Nov). Anthrax outbreaks were relatively higher in the dry (29.4\%) and early dry (27.1\%) seasons than in other seasons.

Table 5. Seasonal distribution of cattle disease outbreaks in SNNPR (2007 - 2015)

\begin{tabular}{|c|c|c|c|c|c|c|c|c|}
\hline \multirow[b]{2}{*}{ Season } & \multirow[t]{2}{*}{ Total outbreaks } & \multicolumn{7}{|c|}{ Diseases } \\
\hline & & Anthrax & Blackleg & CBPP & FMD & HS & LSD & Rabies \\
\hline Long rainy (June-Aug) & $356(23.8)$ & $31(18.2)$ & $148(24.4)$ & $5(41.7)$ & $11(15.5)$ & $100(25.4)$ & $61(25.5)$ & $\mathbf{0}$ \\
\hline Early dry (Sept -Nov) & $459(30.7)$ & $46(27.1)$ & $183(30.1)$ & $1(8.3)$ & 23(32.4) & $104(26.5)$ & $101(42.3)$ & $1(25)$ \\
\hline Dry (Dec-Feb) & 383 (25.6) & $50(29.4)$ & $159(26.2)$ & $1(8.3)$ & $22(31)$ & $100(25.4)$ & $49(20.5)$ & $2(50)$ \\
\hline Short rainy (Mar-May & $298(20)$ & $43(25.3)$ & $117(19.3)$ & 5(41.7) & $15(21.1)$ & $89(22.6)$ & $28(11.7)$ & $1(25)$ \\
\hline Total & 1496 & 170 & 607 & 12 & 71 & 393 & 239 & 4 \\
\hline
\end{tabular}

Values in the parenthesis indicate the proportion of disease outbreaks in each season.

Seasonal distribution of morbidity cases from each cattle disease during the study period has been shown in Table 6.Morbidity cases from all diseases were reported across all the seasons; however, as with outbreak reports, morbidity cases from blackleg, FMD, HS and LSD were relatively higher in the early dry than in other seasons. In contrast, anthrax cases were higher in the short rainy than in other seasons. Although the total cases from CBPP are fewer compared to other diseases, the frequency of occurrence was relatively higher in the long rainy season. 
Table 6. Seasonal distribution of morbidity from each cattle disease outbreak reported in SNNPR (2007 - 2015)

\begin{tabular}{lllllllll}
\hline \multirow{2}{*}{ Seasons } & \multicolumn{9}{c}{ Number (\%) morbidity cases from each disease } & \multicolumn{2}{c}{ Total cases } \\
\cline { 2 - 7 } & Anthrax & Blackleg & CBPP & FMD & HS & LSD & Rabies & \\
Early dry & $329(20.5)$ & $3824(42.1)$ & $30(9.4)$ & $4654(39.8)$ & $2277(39)$ & $7776(48.5)$ & $12(27.9)$ & 18,902 \\
Dry & $374(23.3)$ & $1061(11.7)$ & $13(4.1)$ & $3000(25.6)$ & $1053(18)$ & $1644(10.2)$ & $17(39.5)$ & 7,162 \\
Short rainy & $568(35.4)$ & $2479(27.3)$ & $70(21.9)$ & $2298(19.6)$ & $1150(19.7)$ & $1558(9.7)$ & $14(32.6)$ & 8,137 \\
Long rainy & $333(20.7)$ & $1728(19)$ & $207(64.7)$ & $1748(14.9)$ & $1364(23.3)$ & $5065(31.6)$ & 0 & 10,445 \\
Total & 1604 & 9092 & 320 & 11700 & 5844 & 16043 & 43 & 44,646 \\
\hline
\end{tabular}

Values in parenthesis are proportion of cases from the disease in each season.

\section{Discussion}

Total number of cattle disease outbreaks reports expected from Southern Nations Nationalities and Peoples' Regional State (SNNPRS) during the nine-year's period (2007 to 2015 G.C) was 14,256 but the reports retrieved from MoLF disease data base was only 1,578 (11\%). This shows that $89 \%$ of the reports were missing due to irregularity of reporting by the zones in the region. Based on the available reports a total of 1,496 outbreaks with 44,646 morbidity cases and 4,709 deaths were occurred in cattle in the region from $2007-2015$. The outbreaks were caused by blackleg (40.6\%), HS (26.3\%), LSD (16\%), anthrax (11.4\%), FMD (4.7\%), CBPP (0.8\%), and rabies $(0.3 \%)$ in decreasing order of their proportion which agrees with Berhanu and Shibru, 2016). According to the proportion of morbidity cases observed the diseases were ranked as LSD (35.9\%), FMD (26.2\%), and blackleg (20.4\%), HS (13.1\%) anthrax (3.6\%), CBPP (0.7\%) and rabies $(0.1 \%)$ in descending order.

Analysis of the temporal pattern of disease occurrence over the nine-year period showed a decreasing trend in the number of outbreaks. It is difficult to associate this change with the application of effective control measures such as prophylactic vaccination because the annual vaccination coverage didn't show considerable increase over the reporting period (Mondal and Yamage, 2014). Although disease outbreaks were recorded in all the seasons of a year, more outbreaks were noted in the early dry season (September through November), which comes after the long/heavy rain season (June - Aug) and outbreaks were relatively lower in the short rainy season (Mar-may).

Blackleg was also responsible for the highest proportion of deaths (31\%) over the nine year period and its outbreak was noted in the early dry (30.1\%) season while the lowest in the short rainy $(19.3 \%)$ season. This is nearly similar with the study conducted in India by Sivakumar et al., 2012 (33.03\%) from season March to May. The seasonal occurrence of the disease is mainly observed in early dry (Sept - Nov) (30\%) followed by dry (Dec - Feb) (26\%) seasons which indicated that the occurrence of disease depends on seasons (Andrew and Windsor, 2004). Outbreaks are often associated with alternating heavy rainfall and drought, and high temperatures (Parker et al., 2002). Immature animals and those in good condition are relatively more susceptible and hereditary differences in susceptibility have also been observed (Bayissa et al., 2011).

For this retrospective data, the highest number of outbreak was held by blackleg (40.6\%) followed by heamorrhagic septicemia (26.3\%). Blackleg is associated with areas of high humidity and occurs during rainy seasons. There is an agreement with Sutmoller et al., (2003).

HS was the second major cause of disease outbreak (26.3\%) during the nine year period next to blackleg. It is a fatal septicemia which is influenced by the season of the year. Its incidence was highest during early dry season and similar to the retrospective study conducted in Bangladesh by Mondal and Yamage, (2014) in that HS resulted in high outbreak (34\%) in periods September through November (post-monsoon). The occurrence is mostly in the transition period from wet season to dry or cold weather. The seasonal variations and mortality pattern of Hemorrhagic Septicemia and found that the mean Hemorrhagic Septicemia mortalities increased with increase in rainfall (Sivakumar et al., 2012; Bisht et al., 2006). Moist conditions also prolong the survival of the HS organism (P. multocida), and thus the disease tends to spread more rapidly during the monsoon season when rice cultivation also brings about movements of animals. This concept agrees with the concept of Mondal and Yamage, (2014).

LSD accounted for the highest (35.92\%) proportion of cases over the nine-year period and it was responsible for the highest proportion of deaths (30.2\%) next to blackleg. The proportion of LSD outbreaks (42.3\%) and morbidity cases $(48.5 \%)$ were found to be higher in the early dry season than in other seasons. This result is due to the fact 
that LSD is a viral infectious disease of cattle that disseminate through vectors and this season is favorable for vector (culex mirifinces and others) multiplication/reproduction (Berhanu and Shibru, 2016; Abera et al., 2015).

Although anthrax ranked fourth in its contribution for the outbreaks recorded, it was responsible for the highest case fatality rate $(44.6 \%)$ which contradicts the result of Mondal Yamage, 2014. It is true that anthrax is a peracute disease that causes sudden death in livestock and very important cattle disease among others. Anthrax has great impact in human social life in that it causes wealth loss (per-acute death of cattle), zoonotic importance to human, sometimes ignorance of area where carcass were dropped. Anthrax outbreaks were recorded in all the seasons but more frequently in the early dry (27.1\%) and dry (29.4\%) (Bahiru et al.,2016) seasons than in the short rainy (25.3\%) and rainy seasons (18.2\%). The study conducted in Bangladesh by Mondal and Yamage, (2014) stated that environmental factors, including high ambient temperature and relative humidity that provide a situation for germination of anthrax spores from infected carcasses thrown into flood waters or in open fields may favor the presence of anthrax. The cases of anthrax were seen to occur more commonly in the short rainy (spring season) (35.41\%) than the other seasons. This report relatively agrees with Teklu et al., 2015. This is possibly due to the fact that this season is often hot and the condition is favorable for spore formation, hence, it is likely true that anthrax can relatively occur at higher rate in the short rainy (spring) seasons (Radostits et al. 2007 and Coherence and Fraser, 2006) who stated that animals become readily infected with anthrax, when the minimum daily temperature is above $15^{\circ} \mathrm{C}$. Furthermore, the animals' crowds together at drinking points as water sources become scarce. The outbreak occurred during the hot and humid transition period between the dry season and the wet season. The soil was also significantly disturbed during this time (cultivation season), which possibly disturbed old anthrax grave sites. This agrees with the concept of Shiferaw, (2004).

FMD is one of outbreak occurred in the study area with total proportion of $4.7 \%$. The number of outbreaks increased during early dry and dry seasons, probably due to the favorable environmental conditions of dry weather, dry winds and moderately high relative humidity. This is also the time of the year when migration and movement of livestock is common, especially in rural livestock fairs (Amitha et al., 2014). The disease occurrence is highest in early dry season (Sept - Nov) (32.4\%). Seasonally, the highest number of FMD cases report was found to be registered in early dry season (39.8\%) followed by dry seasons (25.6\%) (Mondal and Yamage, 2014). The reason for the highest occurrence may be due to massive movement of cattle population for seek of pasture and water points. So that, many herds of cattle meets at such places, thereby hastening the spread of infection from one herd to another (Genchwere and Kasanga, 2014).

Generally, outbreaks develop when a large population of susceptible animals is present. If immunized animals are present in the herd, then outbreaks cannot occur until a sufficient number of young, non-resistant animals have been bred or non-immune animals from outside are introduced in the herd (Smith, 1995). Vaccination programs are effective when a large proportion of the population is protected: usually at least $72 \%$ of the susceptible cattle need to be vaccinated (Muleme, 2012).

The result of high proportion rate shows as due to lack of attention for the Prophylaxis Vaccination of animals in the area (Berhanu and Shibru, 2016).

\section{Conclusion and Recommendation}

The retrospective study of disease outbreak data base revealed that anthrax, blackleg, CBPP, FMD, HS, LSD and rabies were the major causes of disease outbreak in cattle in Southern Nation Nationalities and Peoples' Regional State (SNNPRS). However, the reporting rate over the nine year period was noted to be only $11 \%$ and approximately $89 \%$ of disease outbreak reports expected from the region were missed. Based on the retrieved data, blackleg was noted to be the leading cause of disease outbreak in cattle followed by HS while rabies accounted for the least proportion of outbreaks. The occurrence of outbreak was mainly season dependent. Seasonally, the dominant disease outbreak was occurred in early dry season. The vaccination coverage of study area was found to be smaller than the recommend level that is about 1.97 million cattle were vaccinated in nine year's period.

Based on the above conclusion, the following recommendations are forwarded:

- Outbreak investigation in the region was based mainly on symptomatic diagnosis and history from farmers. Thus, veterinarians working at district level need to be supported by confirmatory diagnostic techniques specific to each disease.

- Retrospective study has shown that cattle disease outbreaks occur in all the seasons of the year. This warrants the need for implementation of awareness creation among veterinarians and policy makers and strategic disease prevention program through vaccination, which should be considered before the anticipated season of outbreak for each disease. 
- Since some of cattle diseases were zoonotic and life threatening, enhancing the awareness of livestock keepers about the disease is of paramount importance.

Conflict: There is a high internet access problem in area.

\section{References}

Abera, Z., Degefu, H., \& Gari, G. (2015). Assessment of distribution and associated risk factors of Lumpy Skin Disease in selected district of West Wollega zone, Western Ethiopia. Academic journal of animal disease, 4(3), 130-140.

Amitha, R., Gomes, P., Giridhar, S., Kowalli, B. P., Shivashankar, K. J., Sudharshana, K., ... Venkatesha, C. R. (2014). Epidemiology of foot and mouth disease in Karnataka state, India: a retrospective study, Indian Virological Society, Virus Dis. https://doi.org/10.1007/s13337-014-0239-3

Bahiru, G., Bekele, A., Seraw, B., Boulanger, L., \& Ali, A. (2016). Human and animal anthrax in Ethiopia: A retrospective record review 2009-2013. Ethiopian Veterinary Journal, 20(2), 75-85.

Bayissa, B., Ayelet, G., Kyule, M., Jibril, Y., \& Gelaye, E. (2011). Study on seroprevalence, risk factors, and economic impact of foot-and-mouth disease in Borena pastoral and agro-pastoral system, southern Ethiopia. Trop Anim Health Prod, 43, 759-766. https://doi.org/10.1007/s11250-010-9728-6.

Berhanu, D., \& Shibiru, D. (2016). Most Prevalent Animal Diseases and Their Seasonal Occurrences in East Wollega Ethiopia. African Journal of Basic \& Applied Sciences, 8(4), 240-243. https://doi.org/10.5829/idosi.ajbas.2016. 240 - 243.

BoLFR. (Bureau of Livestock and Fishery Resource) (2016). The Livestock Resource Information Profile. In: SNNPRS, Bureau of Livestock and Fishery Resource, 2015/16).

Bonita, R., Beaglehole, R., \& Kjellstom, T. (2006). Basic epidemiology, supported by WHO (World Health Organization), 2nd edition. Library Cataloguing-in-Publication, ISBN 9241547073 (NLM classification: WA 105) 145-165.

CDC (Center for Disease Control and Prevention) (2012). Principles of Epidemiology in Public Health Practice 3rd Edition an Introduction to Applied Epidemiology and Biostatistics, Centers for Disease Control and Prevention (CDC) Office of Workforce and Career Development Atlanta.

CSA (Central Statistical Agency). (2011). Agricultural Sample Survey, Statistical Agency Federal Democratic Republic of Ethiopia Addis Ababa, 2, 74.

CSA (Central Statistical Agency). (2015). Agricultural Sample Survey 2014/15, Volume II. Report on livestock and livestock characteristics (private peasant holdings). Central Statistical Agency: Addis Ababa, Ethiopia.

Ellis, P. R. (1994). The economics of foot and mouth disease control. In Proc. International Workshop on diagnosis and epidemiology of foot and mouth disease in Southeast Asia. In J. W. Copland, L. J. Gleeson, \& C. Chamnanpood (Eds), 6-9 September 1993, Lampang, Thailand. ACIAR (Australian Centre for International Agricultural Research) Proc. No. 51 (pp. 57-63). ACIAR, Canberra.

ELMP (Ethiopia Livestock Master Plan) (2015). Road maps for growth and transformation. A contribution to The Growth and Transformation Plan II (2015-2020), ILRI Editorial and Publishing Services: Addis Ababa, Ethiopia.

Fasanella, A., Garofolo, G., Hossain, M. J., Shamsuddin, M., Blackburn, J. K., \& Hugh-Jones, M. A. (2011). Anthrax Field Investigation in Bangladesh, Epidemiology \& Infection, 2011, 4-8.

Genchwere, J. M., \& Kasanga, C. J. (2014). Spatial and temporal distribution of foot-and-mouth disease virus in the lake zone of Tanzania. Onderstepoort Journal of Veterinary Research, 81(2), 4. http://dx.doi.org/10.4102/ojvr.v81i2.724

Grace, D., Mutua, F., Ochungo, P., Kruska, R., Jones, K., Brierley, L., Lapar, L., Said, M., Herrero, M., \& Phuc, P. M. (2012). Mapping of poverty and likely zoonoses hotspots. Zoonoses Project 4, report to Department for International Development, UK, International research Institute.

Holleman, C. F. (2002). The socio-economic implications of the livestock ban in Somalia. Famine Early Warning System Network: Nairobi, Kenya.

Hugh-Jones, M. E., \& Blackburn, J. (2009). The ecology of Bacillus anthracis. Molecular Aspects of Medicine in press.

LDMFSB (Livestock Disease Management and Food Safety Brief). (2016). Feed the Future Innovation Lab for 
Livestock Systems Ethiopia, the Management Entity at the University of Florida and U.S Gov"tGlobal Hunger and Food Security 3-14.

Ministry of Livestock and Fishery Resource (MoLFR) (2016). Epidemiology Unit, Diseases Outbreak Database Management profile, from source of $2007-2015$.

Mondal, S. P., \& Yamage, M. (2014). A Retrospective Study on the Epidemiology of Anthrax, Foot and Mouth Disease, Hemorrhagic Septicaemia, Peste des petits Ruminants and Rabies in Bangladesh, 2010-2012. PLoS ONE, 9(8), e104435. https://doi.org/10.1371/journal.pone.0104435.

Mulat, N. B., Basaznew, C., Mersha, M. A., \& Tewodros, F. (2012). Comparison of coprological and postmortem examination techniques for the determination of prevalence and economic significance of bovine fasciolosis. J. Adv. Vet. Res., 2, 18-23.

Muleme, M. (2012). Drivers of infectious disease outbreaks: how climate, environment and disease control programs influence occurrence of infectious disease outbreaks, International Infectious Disease Management and Bio-security, fully published paper, pp 56-78.

PAAHYB (Pan African Animal Health Yearbook) (2010). African Union, Interafrican Bureau for Animal Resources, an AU-IBAR Publication, 10-35.

Parker, R., Mathis, C., Looper, M., \& Sawyer, J. (2002): Anthrax and livestock. Guide B-120. Cooperative Extension Service, College of Agriculture and Home Economics, University of New Mexico: Las Cruces, New Mexico, 1-4.

Radostits, M. O., Gay, C., Hinchcliff., \& Constable, P. D. (2007). Special Medicine, Diseases associated with bacteria - II. In Veterinary Medicine (10th ed), A Text book of the disease of Cattle, Sheep, Goat, pig and horses (pp923-927). Elsevier publishing. W.B. Saunders, London.

Shiferaw, G. (2004). Anthrax in Wabessa village in the Dessie Zuria district of Ethiopia. Rev. sci. tech. Off. int. Epiz., 23(3), 951-956.

Sindato, C., Karimuribo, E., \& Mboera, L. E. (2011). The Epidemiology and Socio-Economic Impact of Rift Valley Fever Epidemics in Tanzania: A Review. Tanzan J. Health Res., 13, 305-318.

Sivakumar, T., Thennarasu, A., \& Rajkumar, J. S. I. (2012). Effect of season on the incidence of infectious diseases of bovine in Tamilnadu. Elixir International Journal, 47, 8874-8875. Retrieved from www.elixirpublishers.com.

Smith, R. D. (1995). Veterinary Clinical Epidemiology - a problem oriented approach. CRC Press, Inc. pp: 187.

Steffen, P., Shirwa, A. H., \& Addou, S. I. (1998). The livestock embargo by Saudi Arabia: a report on the economic, financial, and social impact on Somaliland and Somalia.

Sutmoller, P., Barteling, S. S., Olascoaga, R. C., \& Sumption, K. J. (2003). Control and eradication of foot-andmouth disease. Virus Research, 91, 101-144.

Teklu, A., Hailu, Z., \& Hagos, Y. (2015). A Retrospective Survey and Assessment of Farmers Indigenous Knowledge on Anthrax in and Around Tanqua-Abergelle District, Northern Ethiopia. Academic Journal of Animal Diseases, 4(1), 10-16, https://doi.org/10.5829/idosi.ajad.2015.4.1.91136.

Tuppurainen, S. M. (2005). Detection of the lumpy skin disease virus in samples of the experimentally infected cattle using different diagnostic techniques. J. Vet. Med., 4(8), 247-261.

\section{Copyrights}

Copyright for this article is retained by the author(s), with first publication rights granted to the journal.

This is an open-access article distributed under the terms and conditions of the Creative Commons Attribution license (http://creativecommons.org/licenses/by/4.0/). 